\title{
AN APPROACH TO NOVICE DRIVER TRAINING
}

\author{
A. Ian Glendon, School of Applied Psychology, Griffith University, Gold Coast, \\ Queensland 4222, Australia (Tel: +61 75552 8964; Fax +61 75552 8291; \\ i.glendon@griffith.edu.au)
}

\section{ABSTRACT}

Based upon neuroscience findings relevant to emerging adults, this paper considers 12 cognitive and behavioural features of young drivers' performance and possible ameliorative strategies to address them. Evidence is explored on the extent to which each has been identified and evaluated in respect of young driver training and education in driving performance. The 12 issues are:

1. Providing opportunities to address reward/thrill/sensation/novelty seeking and risk-taking behaviours in "safe" (supervised) environments.

2. Providing opportunities to deal with potentially threatening driving scenarios.

3. Ensuring that young drivers can practise in environments that are "forgiving" of postural lapses.

4. Enabling strategies to ensure supervised practice under night-time conditions.

5. Matching expectations with abilities, particularly under "stressful" conditions.

6. Gradually increasing the range of permitted activities that can be performed safely.

7. Testing for individual differences in risk-taking propensity and educating young drivers about the benefits of subscribing to long-term goals.

8. Providing adequate support and guidance, particularly involving manoeuvres requiring complex decision making.

9. Competence in dealing with hazards and hazard perception tests.

10. Training in hazard/risk perception.

11. "Fast-tracking" the development of mental imagery appropriate to high hazard environments.

12. Providing mentoring and support from older role models, particularly for young male drivers.

The paper considers the extent to which each of these contributions to young driver safety is feasible and has been adopted, identifying those for which further development and implementation is required. Based upon neuroscience findings as 
well as the evidence summarised in this paper, it concludes with an outline of an "ideal" training program for young novice drivers.

KEYWORDS: risk-taking; hazard/risk perception; mentoring; young driver training/education; ameliorative strategies.

\section{UNE APPROCHE POUR LA FORMATION DES CONDUCTEURS NOVICES RÉSUMÉ}

Basé sur les résultats des travaux en neurosciences pertinents pour les jeunes adultes, cet article considère 12 dimensions cognitives et comportementales relatives à la performance de conduite des jeunes conducteurs et des possibles stratégies de les atteindre. Le niveau de preuve est examiné et évalué selon la formation et l'éducation des jeunes conducteurs et les comportements de conduite. Les 12 enjeux sont les suivants:

1. Offrir des possibilités de changer les comportements à risque associés à la recherche de récompense/plaisir/sensations/nouveauté dans des environnements "sûrs" (supervisés).

2. Offrir des possibilités de gérer des scenarii de conduite potentiellement menaçants.

3. S'assurer que les jeunes conducteurs puissent pratiquer dans des environnements qui "pardonnent" leurs défaillances.

4. Développer des stratégies pour assurer des conditions de pratique supervisée de conduite nocturne.

5. Mettre en phase les attentes et les habiletés, en particulier dans des conditions "stressantes".

6. Augmenter progressivement la gamme des activités autorisées qui peuvent être effectuées en toute sécurité.

7. Tester les différences individuelles dans la propension à prendre des risques et éduquer les jeunes conducteurs sur les bénéfices à considérer les objectifs à long-terme.

8. Fournir un soutien et un guidage adéquats, en particulier en ce qui concerne les manouvres nécessitant des prises de décision complexes. 
9. Compétence dans la maitrise des risques et des tests de la perception des risques.

10. Formation à la perception des risques/dangers.

11. "Implémenter" le développement de l'imagerie mentale appropriée aux environnements à haut risque.

12. Offrir en particulier aux jeunes conducteurs de sexe masculin la supervision et l'aide des conducteurs plus âgés.

L'article examine dans quelle mesure chacune de ces dimensions pour la sécurité des jeunes conducteurs est réalisable et a été adoptée. II s'agit d'identifier celles pour qui d'autres développements et d'implémentation sont nécessaires. Sur la base des résultats en neurosciences ainsi que d'éléments probants résumés dans le présent article, on conclut par un aperçu d'un programme de formation "idéal" pour les jeunes conducteurs novices.

MOTS-CLES: prise de risque; perception des dangers/des risques; supervision; formation/éducation des jeunes conducteurs; stratégies pour les atteindre.

\section{INTRODUCTION}

One of the "five pillars" of the Global Plan for the Decade of Action for Road Safety 2011-2020 (United Nations, 2010) is "safer drivers" (others are: road safety management, safer vehicles, safer roads, and post-crash care). Novice drivers are part of the safer drivers component. Driver training typically begins with instilling basic driving skills, followed by further performance development through experience. An objective of this paper is to assess the extent to which a neuroscience-based approach can be matched with empirically-based approaches to driver behaviour and training, through which it might also be expected to identify gaps in research and practice. Notwithstanding research showing that culture may influence certain cognitions and the way in which the brain comes to be wired before and during adolescence (Chiao et al., 2009; Freeman, Rule, Adams, \& Ambady, 2009; Kitayama \& Park, 2010) a neuroscience approach might be expected to have a broadly-based relevance.

As well as revealing that many studies do not have proper control conditions, reviews of evaluation studies of novice driver training (Christie, 2001; Elvik, Høye, 
Vaa, \& Sørensen, 2009; Ker et al., 2008; Langford, 2006; Roberts \& Kwan, 2008; Vernick et al., 1999) have found that improvements in crash rates are rarely detectable as a result of novice driver training programs, and in most cases have been associated with higher crash rates, perhaps as a result of trainees having more driving lessons, earlier licensing and higher risk exposure from more driving. After reviewing the literature, including several reviews of novice driver training, Langford (2006, p. 6) concluded that, "the research suggests that conventional training programs are unlikely to lead to safety benefits. Other options such as extension of practice during periods of supervised driving and the further development of graduated licensing schemes are generally viewed as more promising".

\section{TWELVE WAYS IN WHICH YOUNG NOVICE DRIVERS COULD BE ASSISTED}

Efforts that have been made to address the 12 aspects of cognitive and behavioural features of young drivers' performance and possible ameliorative strategies to address them described by Glendon (2011a) are summarised in Table 1. These components are derived from the author's literature review of neuroscience research as it could relate to driving by drivers aged 16-25 years.

[Table 1 near here]

One key question is: to what extent are neuroscience findings on the developing adolescent brain reflected in empirical research and practical applications in respect of young drivers? Have all developmental neuroscience components already been addressed through empirical research into the cognitions and behaviours of young novice drivers? Or are there gaps - aspects of novice driver performance that have not yet been addressed or that have been researched only to a limited extent? In parallel with these issues is the extent to which neuroscience findings have been reflected in practice, for example the extent to which they are represented in terms of novice driver training (particularly in graduated driver licensing - GDL programs) or the driving test. To address these issues material was sourced from some 20 countries as indicative of research and practice in young driver training. The search was limited to driving-related interventions rather than those designed to address other issues. 
A summary of the evidence located on driving-based interventions is presented in Table 2, which takes the right-hand "strategies" column of Table 1 as the starting point and summarises the identified evidence for research and practice addressing each component. Most of the remainder of the paper expands on the material in the middle and right-hand columns of Table 2, in which the "In practice" column refers to formal driving testing or components of the formal driving instruction process leading to the driving test. Overlaps in some of the sections below may be indicated by cross-references.

\section{[Table 2 near here]}

\section{Providing opportunities to practice in safe (supervised) environments away from driving}

Driver training that aims to improve vehicle handling skills, including manoeuvring and skid pan training, has been relatively ineffective in reducing crash rates. Skid pan training increases crash risk, at least for some drivers, which, inter alia, has been attributed to increased confidence in driving skills, leading to greater risk taking, confirmed by studies in Australia, New Zealand, North America, Europe, and Scandinavia (Christie, 2001; Langford, 2006). What is not known is whether "high risk" activities not associated with driving would have a mitigating effect on driving risk, or whether they too might increase rather than decrease driving risk. Research needs to determine how the impulsiveness and reward orientation of many young drivers can be addressed so as to reduce their propensity to take risks while driving Prato, Toledo, Lotan, \& Ben-Ari, 2010).

In respect of item 1a in Table 2, evidence is required to determine whether risk taking in relatively safe (supervised) environments unconnected with driving (e.g., abseiling, hang gliding) would be effective in respect of sublimating many young drivers' propensity to take risks while driving by addressing their reward-seeking motivation. The three possible outcomes are:

1) It might be associated with increased risk taking while driving.

2) It might be associated with reduced risk taking while driving.

3) It might have no measurable effect either way. 


\section{Providing opportunities to deal with potentially threatening driving scenarios}

An example of this approach is the scenarios delivered via a simulator representing various degrees of threat that were incorporated within the task-analytic approach of Roelofs, van Onna, Brookhuis, Marsman, and de Penning (2011). The "driver" begins with an "accommodating" scene devoid of other participants before being presented with each scenario. Based upon real-life driving situations derived from video sequences of learner drivers under instruction, the 55 scenarios involved dealing with a critical aspect of the traffic or road conditions, which could have had negative consequences if dealt with incorrectly. The scenarios were categorised as: cruising (15), turning (15), merging (8), passing (8), crossing (5), and lane changing (4). Thirty-one of the scenarios referred to a complex decision process, 15 to a complex perceptual process, and nine to a complicated action execution. The scenarios were rated in terms of degree of difficulty and safety by experienced driving instructors. Most were evaluated as difficult for novice drivers. See also Robertson and Kjelsrud (2011, also \#11).

\section{Ensuring that young drivers can practise in environments that are "forgiving" of postural lapses}

Novice drivers frequently gain their initial experience in off-road environments, meaning that when they first drive on the road, encountering traffic might be a relatively novel experience (Liu, 2010; see also \#12). GDL schemes, operating in several jurisdictions, offer one approach to this issue (e.g., Senserrick, 2009; see also \#6). Other possibilities include simulation. For example, Roelofs, van Onna, et al.'s (2011) simulations presented critical traffic situations, which enabled the learner driver to make both safe and unsafe decisions and actions without experiencing the negative consequences.

Senserrick, Yu, Wei, Stevenson, and Ivers (2011) described a driver training program in China that began with basic vehicle handling skills in low-density traffic before proceeding to more complex traffic. Groeger and Brady (2004) reported that off-road driving experience before obtaining a provisional license was associated with first time success in passing the driving test, a finding also reported by Forsyth 
(1992), who found that such practice continued to positively impact subsequent driving test attempts. While learner drivers who drove with their parents were more likely to encounter off-road driving (e.g., car parks, industrial areas, waste ground) as well as back roads and rural roads, with professional instructors they were more likely to experience major roads and more complex traffic (Groeger \& Brady, 2004).

Groeger and Brady (2004) found that the development of driving ability, as measured by total amount of instruction and errors per distance driven, was best represented by a power function. One implication of this finding is that performance improvement is relatively rapid (e.g., substantial error rate reductions) in the initial stages of learning, before slowing considerably as a driver gains experience. The power function also means that while performance continues to improve, it will never become perfect (i.e., be error free), however much experience a driver accumulates.

\section{Enabling strategies to ensure supervised practice under night-time conditions}

Identifying solo night-time driving as a critical risk factor for newly licensed young drivers, Prato et al. (2010) recommended a greater role for parents during the supervised driving stage in ensuring that pre-test novice drivers gained adequate supervised night-time driving experience. While not referring specifically to night-time driving, among others Christie (2001), Langford (2006), and Gregersen, Nyberg, and Berg (2003) have argued for more experience under a greater range of driving conditions, especially when the leaner driver is accompanied by an experienced driver, and has a much reduced crash risk. Groeger and Brady (2004) found that while professional lessons were likely to reoccur at the same time of day, novices drove at less predictable times with non-professional teachers. In their study $90 \%$ of drives with professionals and $74 \%$ of those with family or friends were started between 9:00 am and 6:00 pm. While 15\% of drives with a non-professional teacher occurred after 7:00 pm, only 1\% of drives with a professional instructor occurred after 7:00 pm. While time of drive is confounded by season, in general learner drivers typically had minimal experience of driving outside daylight hours, and nearly all of this experience was with non-professional teachers. In the driver training program described by Senserrick et al. (2011) the final lesson was held during a dark 
evening, and feedback given on the novice driver's performance, including skills that required further development.

Despite the desirability of novice drivers gaining night-time driving experience, several jurisdictions have imposed restrictions on night-time driving as part of GDL provisions (Lin \& Fearn, 2003; Morrisey, Grabowski, Dee, \& Campbell, 2006; Simons-Morton \& Hartos, 2003). For example, the Roads and Traffic Authority of NSW (2011) recommended consideration of introducing a night-time "curfew" driving restriction for P1 drivers (provisional stage lasting for at least 12 months after passing the driving test - subject to zero BAC and unsupervised driving) between 11:00 pm and 5:00 am on Friday and Saturday evenings and investigating the benefits of a similar curfew at other times.

\section{Matching expectations with abilities, particularly under "stressful" conditions}

Researchers in different countries have raised doubts about the validity and reliability of the driving test (e.g., Baughan, Gregersen, Hendrix, \& Keskinen, 2005; Crinson \& Grayson, 2005; Maycock, 2002; Senserrick \& Haworth, 2005). Being more capable of passing the practical driving test is not necessarily the same as being safer or more skilled as a driver (Groeger \& Brady, 2004). These authors argued that the (UK) driving test assesses comparatively basic driving skills and cannot reflect the range of demands that drivers will meet in the future.

Learning with parents and with professional driving instructors involves different experiences so that benefits and disbenefits of each type of driving instruction interact with pupil ability (Groeger \& Brady, 2004). Professional driving instruction is more suited to the needs of less able novice drivers, who respond relatively better to programmatic instruction. More able novices, who benefitted from the more varied, higher speed, reduced instruction and feedback experience more typical of informal instruction, performed better when taught by parents or friends. Professional instructors made relatively more comments about car control, steering and observation, while parents made proportionately more comments about appreciation, vehicle positioning, signaling, and speed (Groeger \& Brady, 2004). 
Groeger and Brady (2004) concluded that novice driver training could be enhanced by optimizing the matching of the novice's learning experience with their needs, and by adapting the way in which novice drivers are taught according to their ability level and certain individual characteristics. This would require preliminary testing of relevant individual characteristics and planning an appropriate combination of professional and private tuition. A combination of these instructional episodes would tend to increase learner drivers' experience of different traffic and driving conditions.

While across all situations professional instructors gave more instruction than private teachers did, the number of comments made by both instructor types to learner drivers and also in the number of driving elements mentioned declined over time (Groeger \& Brady, 2004). However, they pointed out that the inevitably greater volume and complexity of comments early in the learning process coincided with the stage at which learner drivers were least able to process complex verbal information as the driving task competed for memory resources. One possible solution might be to provide a gradual introduction to the driving task so that the amount of instruction could be introduced at a rate commensurate with the learner driver's ability to process it along with driving task requirements.

Groeger and Brady (2004) argued for a combination of the more formulaic professional approach and the less formal style characteristic of private tuition as being optimum for the novice driver to acquire breadth in driving experience. The novice driver has more to listen to during professional instruction, which could result in "over-instruction" due to problems in managing the volume of information. One result is that the pupil may become over-reliant on the instructor rather than developing early driving autonomy. Over-emphasis of formal instruction upon vehicle control, positioning and observation could undermine attempts to develop "higher order" driving appreciation skills (e.g., anticipating other road users' potential actions). While there is evidence that control skills improved as training progressed, from instruction and feedback on errors, this did not necessarily occur for appreciation of other road users' behaviour and traffic laws (Groeger \& Brady, 2004).

A possible model for determining whether a young driver's abilities and expectations are appropriately matched is the 4-level goals for driver education (GDE) matrix (Hattaka, Keskinen, Gregersen, Glad, \& Hernetkoski, 2002), which 
considers knowledge and skill, risk increasing aspects and self-assessment at each of four interacting levels as a global context for driving. The top ("parent") level is concerned with self-identity in terms of life and living goals and skills, the next level addresses goals in the driving context (including fatigue, stress and impairment through alcohol), and the other two are driving in traffic (involving knowledge of road rules and danger anticipation) and vehicle control (the performing or action level, including vehicle handling skills).

\section{Gradually increasing the range of permitted activities that can be performed safely}

The graduated driving literature has dealt with this component fairly extensively (e.g., Mayhew, 2007). Papakosmas and Noble (2011) pointed out that while variants of graduated licensing system (GLS) (or graduated driver licensing, GDL) have been used in Australia, Canada, Sweden, the UK, and the US, there is evidence that such skills- and knowledge-based approaches by themselves are insufficient to reduce younger driver crash rates. These authors pointed out that legislative and regulatory interventions alone (e.g., reduced speed limits, longer training hours) through GLS models may be limited due to their focus on road skills and vehicle management rather than on driver attitudes, which they argued are critical in many road crashes. The most effective GDL components appear to be zero blood alcohol concentration (BAC), restrictions on night-time driving and limiting numbers of peer-passengers (McCarrt, Teoh, Fields, Braitman, \& Hellinga, 2009; Williams, 2007).

In 2007 the Roads and Traffic Authority of NSW (2011) introduced a night-time passenger restriction for $\mathrm{P} 1$ drivers under 25 years of age, which permits only one passenger under the age of 21 between the hours of 11:00 pm and 5:00 am. On the basis of a, "significant reduction in crash and fatality rates involving young drivers over the last decade" (p. 2) the Roads and Traffic Authority of NSW (2011) concluded, "that the RTA's licence testing and regulation has been generally effective". The report pointed out that this reduction has, "coincided with the introduction by the RTA of an enhanced GLS." This suggests correlation but not necessarily causation as a variety of potential influencing factors could have changed during the assessment period. 
The report pointed out that some GLS components have a strong evidential base while others are less well supported by the evidence. For example, the increased minimum duration for a learner's permit, mandating minimum supervised driving hours (see also \#12), zero BAC limit and increasing the minimum duration for a provisional license were considered to be well supported by the evidence. However, imposing a maximum speed restriction on learner drivers was not considered to be well supported by the evidence. The report pointed to a night-time "curfew" for provisional license holders as being a measure that had been supported by evidence elsewhere and recommended considering its adoption in NSW. Country areas were identified as being particularly problematic, as they had higher fatal crash rates than urban areas did. The tenor of the report focused upon enforcement and testing as the prime means of further reducing risk-taking in novice drivers. It also recommended increasing attendance at education workshops for learner driver supervisors to encourage greater parental involvement in the licensing process.

\section{Testing for individual differences in risk-taking propensity and educating young drivers about the benefits of subscribing to long-term goals}

Relevant individual differences might include present/future orientation, locus of control, including fatalism (Girasek, 1999), as well as risk-taking propensity. For example, a fatalistic orientation (to life) might over-ride messages designed to enhance road safety (Kayani, King, \& Fleiter, 2011). Compared with those low in fatalism, high fatalism individuals have been shown to take more risks (Peltzer \& Renner, 2003) and to be more likely to have been road crash victims on multiple occasions (Kouabenan, 1998). Other examples are documented by Kayani et al. (2011).

Groeger and Brady (2004) found that individual differences in speed choice were consistent across driving situations. They surmised that speed choice preferences are established very early in a driver's career, perhaps being accounted for by a combination of such individual characteristics as personality, intelligence, and information processing speed. These authors found that learner drivers who were high in extraversion tended to have a higher proportion of professional instruction in their total driving tuition, which is consistent with the external stimulation typically 
sought by extraverts. Groeger and Brady (2004) also surmised that learner drivers who are high in extraversion were also more likely to be high in traits such as sensation seeking and risk taking.

While reporting that, "there is no known suitable psychological test to be used in the driver licensing context", the Roads and Traffic Authority of NSW (2011) recommended researching the feasibility of using psychological testing for novice drivers, particularly serious and repeat offenders. Kay, Bundy, and Cheal (2011) described a test for evaluating driving performance (DriveSafe/DriveAware), reporting high levels of sensitivity and specificity. Designed to identify levels of cognitive impairment, the test can be delivered to any group of drivers. When validated against on-road performance, such tests, particularly when delivered via touch screen in a short time frame (20 minutes in the case of DriveSafe/DriveAware) could have a potentially valuable and cost-effective role to play in driver screening programs, in rehabilitation, and for assessing trainee drivers.

Moriizumi, Usui, and Nakai (2011) developed a risk propensity questionnaire to determine individuals' propensity to take risks in different aspects of their lives. These authors found that a sample of bus drivers (mean age 34 years) who reported engaging in occasional risk taking (e.g., ignoring a red light as a pedestrian if no vehicles are approaching, riding a bicycle at night without a light, sending a email by cell phone while walking) were significantly more likely to experience crashes in the course of their driving work. However, the direction of "causality" remained problematic.

Roelofs, Vissers, van Onna, and Kern (2011) described three measures to determine a driver's risk profile. The Driver Risk Assessment Questionnaire consists of questions about the driver's behavioural risk factors, including: speed choice under various conditions, lane preference on motorways under various traffic conditions, alcohol use, distraction, fatigue, and anger related to other road users' violations. Total risk score is divided into low, moderate and high risk categories. Driver self-assessment includes questions on strategic, tactical and operational behaviour choices for different road types and the feedback output is an individual profile. The Situation Awareness Test assesses the degree to which a driver is aware of changes in traffic, and comprises 40 traffic scenarios displayed as video clips. Four types of questions are used: recollection (recall of a change in traffic 
situation requiring a correct response to a hazard to solve the situation safely), decision making (selecting the best risk-avoiding solution), localizing hazards (marking the spot where immediate attention is required), and timed response (choosing the optimal moment to carry out a risk-avoiding manoeuvre leaving maximum safety space).

\section{Providing adequate support and guidance, particularly involving manoeuvres requiring complex decision making}

Some countries have increased supervised practice requirements, either in terms of minimum distances driven (e.g., Twisk \& Stacey, 2007) or by number of supervised hours required (Senserrick, 2009). While findings in terms of benefits conferred have been inconsistent, none have been shown to be counterproductive (Twisk \& Stacey, 2007), and protective benefits have been demonstrated (McKnight, Peck, \& Foss, 2002). Senserrick et al.'s (2011) study included feedback on safety behaviours and strategies, as well as educational information, which was also provided in text and DVD format. However, support and guidance is likely to be required over an extended period in order for programmatic effects to be detected (Gregersen et al., 2000; Groeger \& Brady, 2004).

Some countries mandate minimum driving experience and instruction requirements. For example, Freydier, Berhelon, Bastien-Toniazzo, and Gigout (2011) reported that in France, novice drivers must take at least 20 hours of instruction from a driving instructor before being allowed to take a practical driving test. These authors reported that while novice drivers can acquire additional early experience by beginning to drive from age 16 under adult supervision, they must drive a minimum of 3000 kilometres before gaining a full licence, which for any type of training cannot be obtained before age 18. Freydier et al. (2011) found no difference in self-reported risk taking between a sample of young drivers following the traditional instruction route, and those who had acquired additional experience through early training.

Groeger and Brady (2004) found that errors occurring more frequently when parents were the instructors generally involved driving too fast for the road conditions or situation. Errors made with professional instructors were more likely to involve car 
controls and hazard awareness. In general learner drivers' errors were mainly concerned with road positioning (23\% of all errors), observation, including mirror use (19\%), speed control/choice (15\%) and signaling (10\%).

\section{Competence in dealing with hazards and hazard perception tests}

The driver training program described by Senserrick et al. (2011) progressed to higher-order skills, such as situation awareness and hazard perception, to promoting the notion of a "safety cushion" around the vehicle, and scoping visual searches to monitor for more distal hazards. In a comprehensive review, Horswill and McKenna (2004) considered drivers' hazard perception as situation awareness for dangerous conditions, noting that poor hazard perception skills were associated with risk of serious injury crashes. Consistent with the notion that compared with novice drivers experienced drivers conduct more efficient hazard searches, Crundall and Underwood (1998) found that experienced drivers adapted their scanning patterns to different traffic conditions, while novices tended to use the same scanning patterns irrespective of traffic conditions. Compared with experienced drivers, novice drivers also fixated for longer periods, suggesting that they took longer to process information (Crundall \& Underwood, 1998). However, Boccara, Delhomme, VidalGomel, and Rogalski (2011) found that novice drivers' self-assessed driving skills accuracy improved over the four steps of the French driver training course.

Groeger (2000) considered hazard perception to be a pattern matching task, in which experienced drivers have memorized a range of hazardous traffic situations, which can be matched with current information from the driving environment. Rowe (1997) revealed that compared with novice drivers, experienced drivers had a memory advantage for hazardous road conditions. This is consistent with McKenna and Farrand's (1999) finding that, rather than hazard perception becoming more automated with driving experience, experienced drivers require greater attentional resources to achieve their higher level of hazard perception. Novice drivers require a different type of effort to recognize danger, having to infer the danger from first principles using a longer cognitive route (Glendon, 2011a). Summarizing the comparison Horswill and McKenna (2004) explained that, compared with novices, 
experienced drivers' more sophisticated and accurate mental model of driving required greater cognitive resources to apply.

Reviewing the relative reliability of hazard perception tests Horswill and McKenna (2004) reported that hazard perception can be trained using a variety of low cost techniques and queried whether novice drivers are inevitably consigned to elevated risk during the first few years of driving while they acquire hazard perception skills. Horswill and McKenna outlined findings from experimental studies showing that hazard perception training can confer demonstrable benefits. Factors that have been shown to enhance the development of hazard perception skills for novice drivers include:

- Length of training - longer being superior (Sexton, 2002).

- Including event prediction within the training (McKenna \& Crick, 1994).

- Requiring novice drivers to criticize their own performance in visual scanning, hazard prediction and safe decision making (Regan, Deery, \& Triggs, 1998).

- Requiring trainees to attend to a secondary task while maintaining attentional control (Regan et al., 1998).

- Generating running commentaries while driving or viewing videoed driving sequences (Deery, 1999; Gregersen, 1993; Marek \& Sten, 1977; Mills, Hall, McDonald, \& Rolls, 1998; Spolander, 1990).

The aim of this latter type of training is to oblige novice drivers to elaborate their mental model of driving (Horswill \& McKenna, 2004). It has been suggested that different types of hazard perception tests need to be developed for different categories of road users to best represent the type of hazards that they encounter, for example motorcyclists (Haworth, Symmons, \& Kowadlo, 2000).

\section{Training in hazard/risk perception}

Groeger and Brady (2004) found that the extent of pre-driving test professional instruction received by novice drivers affected their perceptions of the danger and difficulty of different driving scenarios. Greater amounts of driving instruction were associated with a higher tendency to interpret descriptions of driving scenarios as dangerous, and less difficult (Groeger \& Brady, 2004). In training sessions, McKenna, Horswill, and Alexander (2006) found that accompanying videoed traffic 
scenes with a recorded commentary by an expert driver reduced novice drivers' risktaking propensity. Guppy, Wilson, and Perry (1990) developed a scale to measure mindful driving style, which relates to such descriptors as being attentive, responsible, safe, and careful. They also developed a calm or cautious driving style scale, which related to such constructs as being placid, patient, considerate, and tolerant.

Hazard perception tests have become part of the driver licensing sequence in a number of jurisdictions, including Australia and the UK (since November 2002). For example, the Roads and Traffic Authority of NSW (2011) use a hazard perception test in the form of a computer touch screen using video footage from a driver's perspective of situations commonly involving provisional licensed drivers in crashes. They recommended considering adding further elements to the Driver Knowledge, Hazard Perception and Driver Qualification tests, reporting that the test was extensively researched by road safety experts prior to development.

\section{1. "Fast-tracking" the development of mental imagery appropriate to high hazard environments}

Describing a study seeking to determine how the Norwegian driving test could be improved, Dalland (2011) noted the importance of the novice driver being able to perceive risk early in the learning cycle. Noting that education can influence cognitions in respect of risk, Dalland reported how driver education in Norway was based on the GDE matrix, involving not just handling a vehicle in traffic, but how this is associated with a driver's motives and goals for life and the environment. In this model, learning to drive is a lifelong process. Thus, the driving education curriculum in Norway emphasizes self-knowledge, life values and attitudes as important to driving competence. Consistent with socio-cultural approaches to learning, the Norwegian curriculum focuses upon the novice driver acquiring competence across all GDE levels (Dalland, 2011). Alongside practical work, activities pursuant to this aim include writing a log, providing opportunities for self-reflection, and considering thoughts behind actions. Reflections about actions occur at three levels: 1) in respect of others, 2) in connection with the learner's own learning process, and 3) internally 
as an expert, so that knowledge is absorbed and reflections can be independently formed in action.

However, Dalland (2011) noted that while the driving education curriculum emphasised reflection and attitudes about actions in the constructivist paradigm, with the teacher being more a coach than an instructor, the driving test remained rooted in the positivist assessment tradition. In a project designed to address this inconsistency, Dalland reported that the project led to the development of a driving test that included self-assessment and commentary driving (e.g., about risk), which some participants reported enhanced their ability to drive and to concentrate. Commentary driving connects self-reflection to actions - the highest level of reflection. There was also approval by both novice drivers and driving examiners for making a short stop during the driving test so that the candidate could reflect on their actions.

Robertson and Kjelsrud (2011) took the use of the GDE matrix a stage further back by considering the reflection of driving instructors and how this could assist in guiding the development of self-awareness of the feelings, intuitions and emotions of novice drivers under their instruction. These authors described the 4-phase driving process model, involving: 1) sensing - gathering information from around the vehicle, 2) perceiving and interpreting hazards correctly, 3) decision - determining the actions to be performed, involving balancing risks and benefits as in a risk assessment (e.g., deciding to go fast despite the presence of a hazard), 4) action the observable component of driving, requiring an appropriate level of skill for execution. While the driving process model involves both mental processes and physical movements, it takes less account of the driver's condition (e.g., level of alertness) and motivation (e.g., to engage in risky behaviours).

Senserrick et al.'s (2011) study included providing information to novice drivers about high-risk scenarios. Insight training focuses on attitudinal and motivational components, with the aim of raising drivers' awareness of factors that contribute to crashes and of the potential risks when driving. Senserrick and Swinburne (2001) reported an evaluation of a driver training program that sought to provide greater insight and awareness of potential risks when driving, thereby targeting overconfidence rather than traditional advanced driving skills, such as vehicle handling and manoeuvring, which have been related to increased crash rates. Repeated 
measures analyses identified several positive changes in attitudes, reported behaviours and perceptions of crash risk. For example, participants' overall confidence in personal driving ability did not increase, with males reporting reduced confidence in their driving ability. However, participants' belief that they were a better driver than others became stronger (it might have been true!). Participants' perceptions of the likelihood of crashing increased, while males' tendency to report driving over the speed limit was reduced. Qualitative feedback included positive changes in reported driving behaviour, including adopting safer speeds, headways and stopping distances, as well as greater awareness of the driving environment.

\section{Providing mentoring and support from older role models, particularly for young male drivers}

A young novice driver might seek to imitate several possible role models. The importance of social influence in collectivist cultures has been demonstrated (e.g., China - Fleiter et al., 2011; Xie \& Parker, 2002). Fleiter et al. found that fathers were reported as being particularly influential as role models for young male drivers, focusing on their attitudes to speeding and avoiding detection and punishment for driving offences. In addition to enabling the novice driver to pass the driving test, the driving instructor was also perceived to exert an important influence on the young driver's driving style. In China drivers can adopt a proactive approach by paying a qualified instructor (accompanying driver) to help them gain on-road experience (Liu, 2010), a program that is being evaluated (World Health Organization, 2011). Mills et al. (1998) used one-to-one instruction for novice drivers with an advanced driving instructor, requiring novice drivers to produce a running commentary as they drove, which improved the novice drivers' hazard perception skills. Support for instructors who act as mentors is also important. For example, Senserrick et al. (2011) reported on the development of a manual for instructors on the novice driver training program that they described.

Peers also play a key role in influencing the novice driver, which could have effects through several pathways, perhaps generating a multiplicative effect. For example, this effect could operate either by directly observing another driver as a passenger (direct role modeling), or as a driver being influenced by a passenger (direct verbal influence), or might be represented as seeking to impress passengers 
with their driving skill (internal modeling) or from following a driver of a vehicle being driven by a friend (direct behavioural modeling). An extreme form of this behaviour is racing among peers, perhaps spurred on by group affiliation. A more diffuse pathway results from modeling an unknown other driver or drivers (indirect behavioural modeling). The latter pathway might be an example of a jurisdiction's driving culture (Zaidel, 1992). Perceptions of competence as a driver (e.g., from peer comments and behaviours) include the ability to handle a vehicle at high speed (Fleiter et al., 2011). Strategies involving social networks to avoid or reduce punishment as a result of being caught violating were also described by Fleiter et al.'s participants. These strategies are relevant from the perspective of potentially undermining the enforcement component of road safety, and merit further investigation.

While it has been known for some time that passengers can have significant effects - positive and negative, on drivers' behaviour (e.g., Baxter et al., 1990), Hutton, Sibley, Harper, and Hunt (2002) determined that one form of mentoring passenger feedback, could be used to change driver behaviour. Two passengers were trained to give verbal feedback to two experienced drivers on speeding, mirror checking, following distance, and hazard checking. Following the interventions, mirror checking increased and following distance improved from baseline to postintervention. While both behaviours had decreased by 4-week follow-up, they remained considerably above baseline levels. While speed choice was the least affected driving behaviour, the authors concluded that for both participants the effect of passenger feedback on targeted driving behaviours was sizeable and sustained and that passenger praise could enhance effectiveness. While passenger feedback has potential as a large-scale low-cost effective means to improve driver behaviour, such programs might only work for drivers who are motivated to improve their driving performance. It would need to be ascertained whether removing passenger feedback might mean that a driver's behaviour reverted - at least partially, to previous levels.

Addressing the issue that young drivers have been found to be more likely to crash when carrying peer passengers, Liu, Lenné, and Williamson (2009) reported findings from a pilot study aimed at improving communication skills between young drivers and their passengers. Training involved a 2-hour facilitated discussion workshop for young male drivers and testing involved a simulator "drive". Compared with an untrained control group, trained participants' headway and speed choice 
were safer, while a higher percentage of the trained group made fewer mistakes and committed fewer violations. Trained passengers made more safe comments than did untrained passengers, confirming that young passengers can be trained to become a more positive influence.

Funk (2011) described outcomes from a German pilot scheme whereby novice drivers aged 17 years could join the "Accompanied drivers from age 17 scheme". As young people can join a driving school at age $16 \frac{1}{2}$ years, and cannot be granted a full license until age 18 years, the accompanied driving scheme means that the driver preparation program in Germany lasts up to 18 months. Accompanying persons must be at least 30 years of age and meet other strict criteria. In nearly all cases (97\%) the accompanying person was a parent. In the German pilot scheme, lasting about eight months, each participant drove approximately 2,400 kilometres (Funk, 2011). While the attendant has no educational role, his/her task is to respond to the novice driver when feedback is requested. Preliminary results indicated that for novice participating drivers, reported feelings of security while driving increased. Also reported was improved vehicle control, better anticipation of other road users' behaviour and a more confident driving style, particularly when compared with less experienced novice drivers. The scheme was also integrated within the age-specific phase of the young drivers' lives.

Irrespective of cultural factors, a key issue is the extent to which a driver can select their preferred driving behaviour under any circumstances and remain true to that position (neuropsychological evidence for when this starts to become the dominant form of cognition-influenced behaviour is about age 22 years, but with substantial individual variation) (Fleiter, Lennon, \& Watson, 2007). As a possible safe driving slogan, "Be your own person" might reflect this approach in a motivational campaign.

A related developmental approach to training via mentoring is that of coaching. Roelofs, Vissers, et al. (2011) observed that the instructor becomes a driving coach when they switch from a direct instruction and immediate feedback approach to training by adopting an approach that emphasises the development of higher order skills in the trainee driver, including increasing self-regulation. Coaching involves stimulating and supporting self-regulated learning, for example by asking questions and providing feedback on learning activities as employed by the trainee. The criteria 
for driving proficiency derived by Roelofs, Vissers, et al. (2011) were: 1) safety incorporating indicators of situation awareness, correct timing of actions, adapting speed, and using "space cushions", 2) facilitating traffic flow, 3) consideration of other road users - without showing aggression or irritation, 4) controlled driving, and 5) environmentally-responsible driving - including optimal fuel use and minimizing noise levels and harmful gas emissions.

Haythorpe (2011) described an Australian initiative (Keys2drive) comprising a free driving lesson by an accredited driving instructor to learner drivers, accompanied by their supervising driver (e.g., parent). Based on a coaching approach, the method encourages the novice driver to be proactive in their learning. A superficial program evaluation was undertaken by telephoning a sample of 200 learners and supervisors to obtain responses to seven questions, which returned a preponderance of positive responses. The program is supported by web-based material, including a social networking site.

The importance of parents as role models in driving is considerable, not just at the point at which they teach their children to drive, but critically also during the years up to that point. The link between parents' driving habits, particularly negative ones, and those of their children has been known for some time (Bianchi \& Summala, 2004; Ferguson, Williams, Chapline, \& Reinfurt, 2001). Papakosmas and Noble (2011) recruited novice drivers and their parents to participate in focus groups. The authors found that the parents' modeling of negative driving behaviours conflicted with the safe driving habits that they attempted to teach their children. It was also found that when acting as driving instructors, parents struggled with confidence, competence and communication issues.

Themes emerging from Papakosmas and Noble's (2011) study were: 1) parental driver modeling in pre-learner and learner stages, 2) parents' skills as driving instructors, 3) the communication gap between what young drivers say they need (parental involvement) and what they demand of their parents (driving freedom), and 4) the freedom milestone represented by a driver's license when young people are seeking independence from their family. Papakosmas and Noble recommended reshaping the meaning of this milestone, so that rather than being perceived as a route to freedom and independence, which could be associated with riskier driving, it could be marketed as a means to achieve greater maturity, represented by 
responsible attitudes and behaviours. The emphasis would be upon driving as an important component of self-development to become a safe and responsible member of society.

Papakosmas and Noble's (2011) findings indicated a number of troubling issues concerning parents' ability to provide adequate mentoring for their children, both at the pre-licence phase and subsequently. There was mutual apprehension by both novice drivers and their parents in terms of the parents' effectiveness as driving instructors. These authors argued for social marketing to target parents of young children to make them aware of how their driving habits could influence their children. While NSW websites devoted some resources to this end, the evidence from this study indicated that parents were not accessing this information or felt that it did not meet their needs as driving instructors.

In 2007 the NSW government added to the state GLS by requiring learner drivers to complete 120 hours of supervised driving. The Roads and Traffic Authority of NSW (2011, p. 5) reported that, "The RTA currently funds Youthsafe, a not-for-profit organization, to develop injury prevention programs. Since 2009 Youthsafe has assisted community-based organistions deliver learner driver mentor programs. This year, Youthsafe will publish an operational manual for community-based learner driver mentoring programs. Next year, Youthsafe will provide road safety and program training for up to 10 community-based mentoring programs which provide on-road driving experience to disadvantaged youth."

\section{Evaluating young driver training programs}

While the importance of evaluating driver training programs is frequently acknowledged, only a small proportion of such programs are systematically evaluated and reported in the scientific literature (Glendon, 2011b). Evaluating attempts to improve young driver training programs continues to be the exception rather than the norm, but evaluation studies are essential for evidence-based progress to occur. Of schemes that are evaluated, many use only participant feedback, while comparatively few are evaluated in terms of behavioural outcomes (e.g., crash rates, cited violations, traffic related fines, insurance claims, prosecutions, convictions for driving offences (e.g., speeding, drink-driving), and 
driver's licence demerit points), or at a skill-based level (e.g., using simulation). Reasons for the dearth of driving evaluation studies might include:

1) Despite potential benefits (e.g., enhanced commercial opportunities) it may be difficult to recruit commercial or voluntary driver training organisations that are willing for their programs to be evaluated, for example because they are averse to the possibility that no benefits will be detectable, particularly in the longer term.

2) Road traffic authorities may be unwilling to devote resources to evaluating their road safety programs or to research interventions if these do not match their current policy environments, for example in terms of perceived political priorities.

3) Because evaluation research is relatively expensive, typically involving developing intervention programs and repeat measures designs (at least three sets of data points are required for a longitudinal study), it may be difficult for independent researchers to obtain funding for such studies. This tends to lead to short-term 'experimental' research (e.g., using simulation) that is easier to fund, facilitates data gathering, and has more certain publication outcomes.

4) Random selection of participants is rarely achievable in field studies, leaving the possibility that antecedent conditions (e.g., motivation for safe behaviour) cannot be excluded as a confounding factor. Where program effects are demonstrated ethical conditions may require offering control participants the complimentary safe driving training program.

5) Some countries have privacy legislation (e.g., Australia) that makes it difficult to match survey and driver training program data with outcome data that could be used as criterion variables (e.g., as listed above).

\section{Developing a framework for young novice driver training}

The foregoing discussion leads to the conclusion that while some neuroscience findings about the adolescent and emerging adult brain have been addressed through empirical research, and a few have been incorporated within novice driver training in a few jurisdictions, the overall picture is of a very piecemeal approach, with many aspects identified barely addressed at all. In an attempt to demonstrate how neuroscience findings might provide a framework for an 'ideal' novice driver 
training program, Figure 1 incorporates the key findings into a proposed logical structure for training young novice drivers.

[Figure 1 near here]

Figure 1 does not indicate the stage at which a formal driving test should be undertaken. This deliberate omission is based on the grounds that because of individual differences between young drivers, the point at which a formal test will be appropriate will inevitably differ. The approach represented in Figure 1 is developmental rather than prescriptive in terms of when the novice driver is considered to be sufficiently competent and mature to be permitted a license that allows unaccompanied driving. As a graduated approach it seeks to remove the sudden delivery of a "fully competent driver" by substituting this with a model indicative of a developmental process rather than a stepped change approach. Each stage of the model should be tested through rigorous research prior to implementation.

\section{CONCLUSIONS}

Traffic psychologists are in the early stages of developing concepts, models, measures, tests and programs that will be useful in improving young driver training and safety. Of those that have been developed, some have demonstrated their effectiveness in practice (e.g., GDL/GLS in combination with other measures). Many others are at developmental stages, and some show considerable promise (e.g., extended practice with an accompanying driver, hazard/risk perception training).

Traffic authorities throughout the developed world are currently "experimenting" with a wide range of strategies and techniques to address the "young driver problem". The next 10-15 years are likely to see a substantial increase in the number of evaluation studies as these various schemes are trialed and tested. Traffic psychologists are increasingly using their skills and research methodologies to work with local authorities to develop and evaluate driver safety initiatives. More evaluation studies are required to establish a robust evidence-based framework for developing practical and relevant young driver training programs.

While there are a few hopeful signs that some developing countries are beginning to appreciate the costs of road deaths and the benefits of addressing this issues, to 
date most major advances in young driver training have been in developed economies. There is substantial evidence from a few countries that traditional training-based approaches (e.g., instruction, immediate feedback on errors) to novice driver training are being augmented, and in some cases beginning to be supplanted, by concept-based approaches in which the novice driver is treated as an active empowered agent in their learning over an extended period beginning some time before the standard driving text and lasting for a period beyond the test, often within the context of a mentoring or coaching program.

It remains to be determined whether legislated changes, such as GDL (GLS) which impose greater restrictions on driving conditions, are complementary to, or in conflict with empowerment developments, in which the young novice driver is treated as an active learning agent. While conceptually they are in conflict, they may be considered as complementary approaches, even though they operate from different assumptions about behaviour. This is partly because young drivers are not a homogeneous group (a growing body of research attests that this is the case, based for example on attitude, personality and other group and individual differences) so that diverse strategies are likely be effective for different groups. For some young drivers the threat and reality of penalties and sanctions will be the most effective way of controlling their behaviour. For others, it will be being given the responsibility to drive safety that provides the prime motivation.

An approach to young novice driver training based on generic neuroscience research findings on the development of adolescent and emerging adult brains offers a potentially useful "checklist" of issues. Together with empirical evidence from the young driver literature, it could form the basis of a model to be tested within the context of a systematic framework for novice driver training programs.

\section{REFERENCES}

(bracketed numbers after each reference refer to the sections in the main body of the paper for which it is relevant)

Baughan, C., Gregersen, N. P., Hendrix, M., \& Keskinen, E. (2005). Towards European standards for testing. (Final report). Brussels: Commission Internationale des Examens de Conduite Automobile. (5)

Baxter, J. S., Manstead, A. S. R., Stradling, S. G., Campbell, K. A., Reason, J. T., \& Parker, D. (1990). Social facilitation and driving behaviour. British Journal of Psychology, 82, 351-360. (12) 
Bianchi, A., \& Summala, H. (2004). The "genetics" of driving behavior: Parents' driving style predicts their children's driving style. Accident Analysis and Prevention, 35, 655-659. (12)

Boccara, V., Delhomme, P., Vidal-Gomel, C., \& Rogalski, J. (2011). Development of student drivers' self-assessment accuracy during French driver training: Selfassessments compared to instructors' assessments in three risky driving situations. Accident Analysis \& Prevention, 43(4), 1488-1496.

Chiao, J. Y., Harada, T., Komeda, H., Li, Z., Mano, Y., Saito, D., Parrish, T. B., Sadato, N., \& lidaka, T. (2009). Neural basis of individualistic and collectivistic views of self. Human Brain Mapping, 30, 2813-2820.

Christie, R. (2001). The effectiveness of driver training as a road safety measure: $A$ review of the literature. (Report No. 01/03). Noble Park, Victoria: Royal Automobile Club of Victoria.

Crinson, L. F., \& Grayson, G. B. (2005). Profile of the British learner driver. In G. Underwood (Ed.), Traffic and transport psychology: Theory and application (pp. 157-170). Oxford; Elsevier. (5)

Crundall, D. E., \& Underwood, G. (1998). Effects of experience and processing demands on visual information acquisition in drivers. Ergonomics, 41, 448-458. (9)

Dalland, E. B. (2011). The driving test in Norway: A tension between curriculum and assessment. In L. Dorn (Ed.), Driver behaviour and training (Vol V, in press). Aldershot, UK: Ashgate. $(7,11)$

Deery, H. A. (1999). Hazard and risk perception among young novice drivers. Journal of Safety Research, 30(4), 225-236. (9)

Elvik, R., Høye, A., Vaa, T., \& Sørensen, M. (2009). The handbook of road safety measures (2nd. Edn.). Bingley, UK: Emerald.

Ferguson, S., Williams, A., Chapline, J., \& Reinfurt, D. (2001). Relationship of parent driving records to the driving records of their children. Accident Analysis and Prevention, 22, 229-234. (12)

Fleiter, J. J., Lennon, A., \& Watson, B. (2007). Choosing not to speed: A qualitative exploration of differences in perceptions about speed limit compliance and related issues. In Australasian Road Safety Research Policing and Education Conference, Melbourne, 17-19 October. (12)

Fleiter, J. J., Watson, B., Lennon, A., King, M., \& Shi, K. (2011). Social influences on drivers in China. Journal of the Australasian College of Road Safety, 22(2), 2936. (12)

Forsyth, E. (1992a). Cohort study of learner and novice driver types, part I: Learning to drive and performance in the driving test. (Department of Transport TRL Report RR 372). Crowthorne, UK: Transport Research Laboratory. (3, 8)

Freeman, J. B., Rule, O. N., Adams, R. B., \& Ambady, N. (2009). Culture shapes a mesolimbic response to signals of dominance and subordination that associates with behavior. Neurolmage, 47, 353-359. 
Freydier, C., Berhelon, C., Bastien-Toniazzo, M., \& Gigout, E. (2011). The Driver Behaviour Questionnaires: A French study on young drivers. In L. Dorn (Ed.), Driver behaviour and training (Vol V, in press). Aldershot, UK: Ashgate. (8)

Funk, W. (2011). Accompanied driving from age 17 - A new scheme for young novice drivers in Germany. In L. Dorn (Ed.), Driver behaviour and training (Vol V, in press). Aldershot, UK: Ashgate. (2, 3, 8, 12).

Girasek, D. C. (1999). How members of the public interpret the word "accident". Injury Prevention, 5, 19-25. (7)

Glendon, A. I. (2011a). Neuroscience and young drivers. In B. Porter (Ed.), Handbook of traffic psychology (pp. 109-125). Amsterdam: Elsevier.

Glendon, A. I. (2011b). Traffic psychology: A state-of-the-art review. In P. R. Martin, F. M. Cheung, M. C. Knowles, M. Kyrios, L. Littlefield, J. B. Overmier, \& J. M. Prieto (Eds.), The IAAP handbook of applied psychology (pp. 545-558). Oxford: Wiley-Blackwell.

Gregersen, N. P. (1993). Integrated driver education: An experiment with systematic cooperation between traffic schools and private teachers. (VTI Rapport 376). Linköping: Swedish Road and Transport Institute. (9)

Gregersen, N. P., Berg, H-Y., Engstrom, I., Nolen, S., Nyberg, A., \& Rimmo, P. A. (2000). Sixteen years age limit for learner drivers in Sweden - An evaluation of safety effects. Accident Analysis and Prevention, 32, 25-35. (8)

Gregersen, N. P., Nyberg, A., \& Berg, H-Y. (2003). Accident involvement among learner drivers - An analysis of the consequences of supervised practice. Accident Analysis and Prevention, 35, 725-730. (4, 12)

Groeger, J. A. (2000). Understanding driving. Hove, UK: Psychology Press. (9)

Groeger, J. A., \& Brady, S. J. (2004). Differential effects of formal and informal driver training. (Road Safety Research Report No. 42). London: Department for Transport. $(2,3,5,7,8,12)$

Guppy, A., Wilson, P., \& Perry, J. (1990). Drivers' attitudes and driving experience. In Driving behaviour in a social context: proceedings of the International Symposium organized by La Prévention Routière, 16-18 May 1989, Paris. (pp. 181-189). Caen, France: Éditions Paradigme. (10)

Hattaka, M., Keskinen, E., Gregersen, N-P., Glad, A., \& Hernetkoski, K. (2002). From control of the vehicle to personal self-control: Broadening the perspectives to driver education. Transportation Research Part F: Traffic Psychology and Behaviour, 5, 201-215. $(2,5,11)$

Horswill, M. S., \& McKenna, F. P. (2004). Drivers' hazard perception ability: Situation awareness on the road. In S. Banbury \& S. Tremblay (Eds.), A cognitive approach to situation awareness: Theory and application (pp. 155-175). Aldershot, UK: Ashgate. (9)

Haworth, N., Symmons, M., \& Kowadlo, N. (2000). Hazard perception by inexperienced motorcyclists. (Research Report). Monash University, Melbourne: Monash University Accident Research Centre. http://www.monash.edu.au/oce/roadsafety (9) 
Haythorpe, B. (2011). Keys2drive: An evolution or revolution in the way Australian learner drivers are taught? Journal of the Australasian College of Road Safety, 22(1), 29-32. (12)

Hutton, K. A., Sibley, C. G., Harper, D. N, \& Hunt, M. (2002). Modifying driver behaviour with passenger feedback. Transportation Research Part F: Traffic Psychology and Behaviour, 4, 257-269. (12)

Kay, L. G., Bundy, A. C., \& Cheal, B. (2011). DriveSafe/DriveAware: A promising new off-road test to predict on-road performance. In L. Dorn (Ed.), Driver behaviour and training (Vol V, in press). Aldershot, UK: Ashgate. (7)

Kayani, A., King, M. J., \& Fleiter, J. J. (2011). Fatalism and road safety in developing countries, with a focus on Pakistan. Journal of the Australasian College of Road Safety, 20(2), 41-47. (7)

Ker, K., Roberts, I. G., Collier, T., Beyer, F. R., Bunn, F., \& Frost, C. (2008). Postlicence driver education for the prevention of road traffic crashes (Review). The Cochrane Collaboration, 3. Wiley.

Kitayama, S., \& Park, J. (2010). Cultural neuroscience of the self: Understanding the social grounding of the brain. Social Cognitive and Affective Neuroscience, 5, 111-129.

Kouabenan, D. R. (1998). Beliefs and the perception of risks and accidents. Risk Analysis, 18, 243-252. (7)

Langford, J. (2006). Road safety implications of further training for young drivers. Melbourne: Monash University Accident Research Centre.

Lin, M.L., \& Fearn, K.T. (2003). The provisional license: Nighttime and passenger restrictions-a literature review. Journal of Safety Research, 34(1), 51-62. (4)

Liu, C. (2010). Chinese novice drivers can receive free on-road training. Sydney: The George Institute for Global Health. Retrieved from http://www.georgeinstitute.org/about-us/media-centre/chinese-novice-drivers-canreceive-free-\%E2\%80\%9C-road\%E2\%80\%9D-training $(1,12)$

Liu, C. C., Lenné, M. G., \& Williamson, A. R. (2009). Development and evaluation of a young driver training program. Melbourne: Monash University Accident Research Centre. (12)

Marek, J., \& Sten, T. (1977). Traffic environment and the driver: Driver behavior and training in international perspective. Springfield, III: Charles C. Thomas. (9)

Maycock, G. (2002). Novice driver accidents and the driving test. Crowthorne, UK: Transport Research Laboratory. (5)

Mayhew, D. R. (2007). Driver education and graduated licensing in North America: Past, present and future. Journal of Safety Research, 38, 229-235. (6)

McCarrt, A., Teoh, E., Fields, M., Braitman, K., \& Hellinga, L. (2009). Graduated licensing laws and fatal crashes of teenage drivers: A national study. Arlington, VA: Insurance Institute for Highway Safety. (6)

McKenna, F. P., \& Crick, J. L. (1994). Developments in hazard perception. (Final Report). London: Department for Transport. (9) 
McKenna, F. P., \& Farrand, P. (1999). The role of automaticity in driving. In G. B. Grayson (Ed.), Behavioural research in road safety IX. Crowthorne, UK: Transport Research Laboratory. (9)

McKenna, F. P., Horswill, M. S., \& Alexander, J. L. (2006). Does anticipation training affect drivers' risk taking? Journal of Experimental Psychology - Applied, 12, 110. (10)

McKnight, A. J., Peck, R. C., \& Foss, R. (2002). Graduated driver licensing: What works? Injury Prevention, 8(Suppl II), 32-38. (8)

Mills, K. L., Hall, R. D., McDonald, M., \& Rolls, G. W. P. (1998). The effects of hazard perception training on the development of novice driver skills. (Research Report). London: Department for Transport. http://www.dft.gov.uk $(9,12)$

Moriizumi, S., Usui, S., \& Nakai, H. (2011). Relationship between the tendency of young commercial drivers to take risks in daily life and accident involvement. In $\mathrm{L}$. Dorn (Ed.), Driver behaviour and training (Vol V, in press). Aldershot, UK: Ashgate. (7)

Morrisey, M. A., Grabowski, D. C., Dee, T. S., \& Campbell, C. (2006). The strength of graduated drivers license programs and fatalities among teen drivers and passengers. Accident Analysis and Prevention, 38(1), 135-141. (4)

Papakosmas, M. F., \& Noble, G. (2011). Parents and young drivers: the role of learning, behaviour modeling, communication and social marketing. Journal of the Australasian College of Road Safety, 22(1), 45-52. (6, 12)

Peltzer, K., \& Renner, W. (2003). Superstition, risk-taking and risk perception of accidents among South African taxi drivers. Accident Analysis and Prevention, 35, 619-623. (7)

Prato, C. G., Toledo, T., Lotan, T., \& Taubman-Ben-Ari, O. (2010). Modeling the behavior of novice young drivers during the first year after licensure. Accident Analysis \& Prevention, 42(2), 480-486.

Regan, M., Deery, H. A., \& Triggs, T. (1998). Training for attentional control in novice car drivers: A simulator study. In Proceedings of the Human Factors and Ergonomics Society $42^{\text {nd }}$ Annual meeting (pp. 1408-1413). Chicago, October 59. (9)

Roads and Traffic Authority of New South Wales (2011). Improving road safety: Young drivers. Performance audit - New South Wales Auditor General's Report. The Audit Office of New South Wales. $(4,6,7,10,12)$

Roberts, I. G., \& Kwan, I. (2008). School-based driver education for the prevention of traffic crashes (Review). The Cochrane Collaboration, 4. Wiley.

Robertson, K., \& Kjelsrud, H. (2011). Using reflecting team as a method to focus on state of mind and emotions and how it affects our actions. In L. Dorn (Ed.), Driver behaviour and training (Vol V, in press). Aldershot, UK: Ashgate. $(2,3,11)$

Roelofs, E., van Onna, M., Brookhuis, K., Marsman, M., \& de Penning, L. (2011). Designing developmentally tailored driving assessment tasks for formative pruposes. In L. Dorn (Ed.), Driver behaviour and training (Vol V, in press). Aldershot, UK: Ashgate. $(2,3,7)$ 
Roelofs, E., Vissers, J., van Onna, M., \& Kern, G. (2011). Coaching young drivers in a second phase training programme. In L. Dorn (Ed.), Driver behaviour and training (Vol V, in press). Aldershot, UK: Ashgate. $(7,12)$

Rowe, R. M. (1997). Anticipation in skilled performance. Unpublished PhD thesis. Reading, UK: University of Reading. (9)

Senserrick, T. (2009). Australian graduated driver licensing systems. Journal of the Australasian College of Road Safety, 20(1), 20-26. (1, 6, 8)

Senserrick, T., \& Haworth, N. (2005). Review of literature regarding national and international young driver training, licensing and regulatory systems. (RFQ No. DPC803). Melbourne: Monash University Accident Research Centre. (6)

Senserrick, T. M., \& Swinburne, G. C. (2001). Evaluation of an insight driver training program for young drivers. (Report No. 186). Melbourne: Monash University Accident Research Centre. $(1,11)$

Senserrick, T., Yu, X., Wei, D., Stevenson, M., \& Ivers, R. (2011). Development of a supplementary education and training program for novice drivers in China. Journal of the Australasian College of Road Safety, 22(2), 36-41. (3, 4, 5, 8, 11 , 12)

Sexton, B. (2002). Evaluation of hazard perception testing. Crowthorne, UK: Transport Research Laboratory.

Simons-Morton, B. G., \& Hartos, J. L. (2003). How well do parents manage young drivers? Journal of Safety Research, 34(1), 91-97. (4)

Spolander, (1990). Effects of commentary driving: A study on young male drivers. (VTI Rapport 359). Linköping: Swedish Road and Transport Institute. (9)

Twisk, D. A. M., \& Stacey, C. (2007). Trends in young driver risk and countermeasures in European countries. Journal of Safety Research, 38, 245257. $(8,12)$

United Nations. (2010). Global plan for the decade of action for road safety 20112020. Available from http://www.who.int/roadsafety/decade of action/plan/plan en.pdf

Vernick, J. S., Li, G., Ogaitis, S., MacKenzie, E. J., Baker, S. P., \& Geilen, A. C. (1999). Effects of high school driver education on motor vehicle crashes, violations, and licensure. American Journal of Preventive Medicine, 16(Suppl I), 40-46.

Williams, A. F. (2007). Contribution of the components of graduated licensing to crash reductions. Journal of Safety Research, 38, 177-184. $(6,8,12)$

World Health Organization. (2011). China novice driver training pilot study clinical trial registration ChiCTR-TRC-10000800. The George Institute for International Helath. Retrieved from http://apps.who.int/trialsearch/trial.aspx?triald= ChiCTRTRC-10000800 (12)

Xie, C., \& Parker, D. (2002). A social psychological approach to driving violations in two Chinese cities. Transportation Research Part F: Traffic Psychology and Behaviour, 5, 293-308. (12)

Zaidel, D. M. (1992). A modeling perspective on the culture of driving. Accident Analysis and Prevention, 24, 585-597. (12) 
STAGE

PRE-

TRAINING

CLASSROOM/

SIMULATION

CONTROLLED

TRACK

ENVIRONMENT

ON-ROAD

ENVIRONMENT

FOLLOW-UP

SOCIO-LEGAL

FRAMEWORK

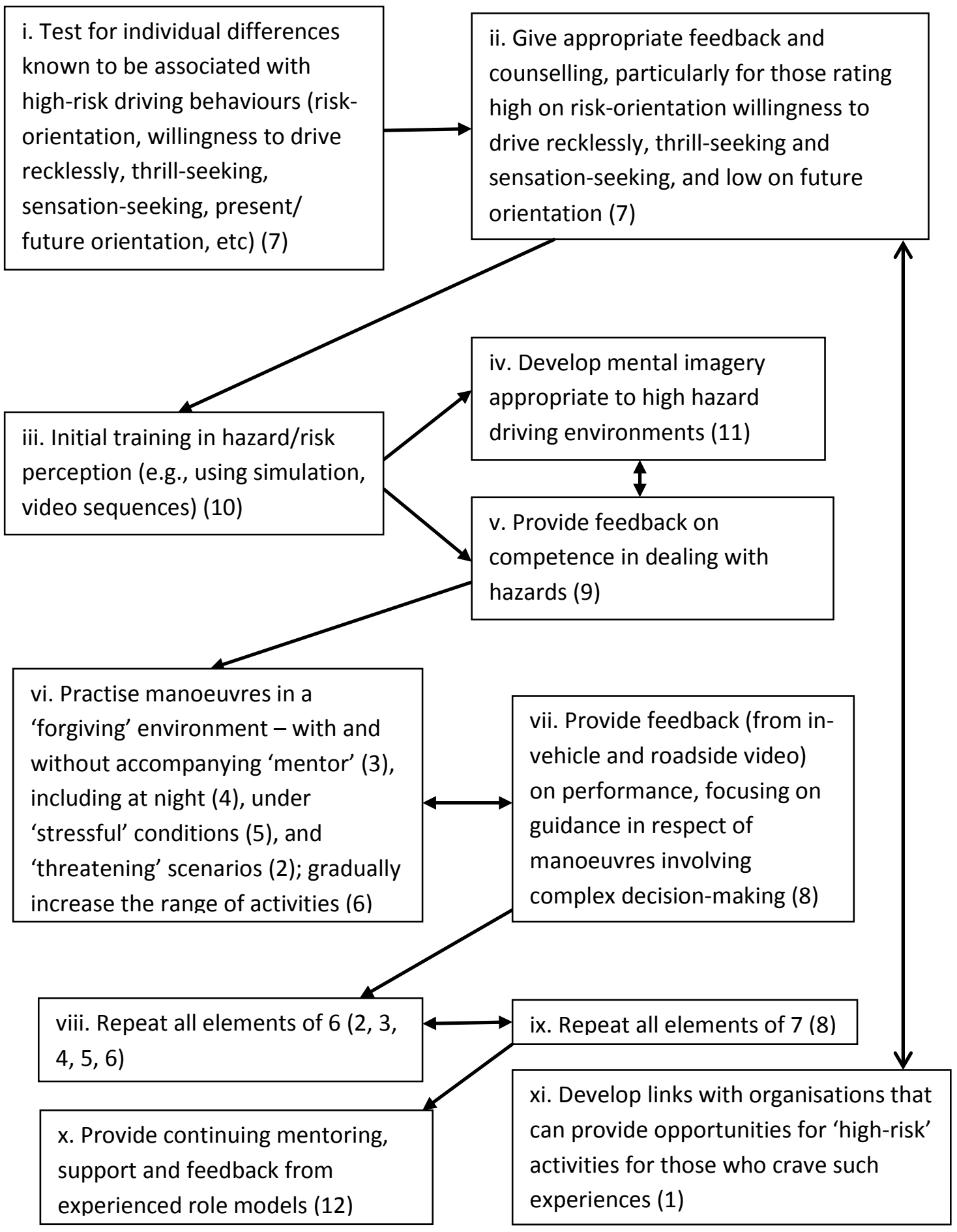

xii. Gradually increase range of permitted activities that can be performed safely (e.g., via GDL, number of passengers, night-time driving, alcohol limits, in-vehicle distractions - mobile phone, etc use) (6) + campaigns targeted at increasing: a) parental awareness of influence and b) driving instructor awareness + first aid training 
Figure 1. "Ideal" young novice driver training program based on neurological developmental research findings (bracketed numbers refer to features identified in Table 1) 